\title{
Optimization of maps from public transport information systems
}

\author{
Vit Vozenilek ${ }^{\mathrm{a}, *}$ \\ ${ }^{a}$ Palacky University Olomouc, Vit Vozenilek - vit.vozenilek@upol.cz \\ * Corresponding author
}

\begin{abstract}
:
Schematic maps still have a strong position in passenger information systems. Even at the time of easily accessible, individually available mobile applications for public transport journey planning and navigation. Their potential is in a unique graphic design that attracts the attention of all generations of passengers. To effectively use, schematic maps, it is appropriate to optimize their creation process and to pay attention to the user aspect using analytical approaches, such as those used in the paper. The paper dealt with analyzing the maps from public transport information systems. An emphasis is given the influence of schematization on the perception for increasing the effectiveness of the maps. More than 80 collected schematic maps were classified according to the schematic criteria and methods of expression. Attention was focused on user analysis. An eye-tracking experiment was performed on current maps as stimuli, of which 20 were for the free viewing and with 15 questions. It consisted of three types of questions on labels, lines, points, and overall network orientation. Testing with 15 respondents was preceded by pilot testing with five respondents. Statistical analysis of the experiment showed differences in the perception of maps by respondents and problematic aspects of methods of expression and their use in schematic maps. In addition, three questionnaires were compiled to look into the approach of users, the author's approach and the approach of transport organizations to the issue of the use of maps in passenger information systems. The last step of the analysis was a moderated interview with a focus group with five respondents. The results of these parts were used to formulate the optimization of mapping, which is presented in the form of nine steps of an effective mapping process. This proposed method was used to create a prototype map of the public transport system in Olomouc. The paper points out the possibilities of map creation, clearly defines the basic steps necessary to create an ideal schematic map and point out the fact that even in amateur conditions can be achieved satisfactory results. The aim is not to specify a standard or a literal manual. In the following paragraphs, only the basic steps and some possibilities of how to approach their solution are summarized, while still retaining space for the author's own graphic expression. The paper was compiled within the Czech Scientific Foundation project No 18-05432S „Spatial synthesis based on advanced geocomputation methods".
\end{abstract}

